\title{
Research Paper: The Role of Cultural Intelligence on Self-esteem and Family Conflict Resolution Among Athletes
}

\author{
Fahmideh Soltani $^{1}$ (D, Zohreh Meshkati $^{1^{*}}$ (D)
}

1. Department of Motor Behavior, Faculty of Physical Education and Sport Sciences, Isfahan (Khorasgan) Branch, Islamic Azad University, Isfahan, Iran.

Citation Soltani F, Meshkati Z. The Role of Cultural Intelligence on Self-esteem and Family Conflict Resolution Among Athletes. Journal of Research \& Health. 2021; 11(2):95-104. http://dx.doi.org/10.32598/JRH.11.2.1645.1

: http://dx.doi.org/10.32598/JRH.11.2.1645.1

\section{(i) (3)}

Article info:

Received: 19 Jan 2019

Accepted: 24 Nov 2019

Publish: 01 Apr 2021

\section{Keywords:}

Culture, Intelligence, Self esteem, Family conflicts, Athlete

\section{A BSTRACT}

Background: Regarding the importance of resolving family problems in athletic progress and identifying the underlying factors, the purpose of this study was to investigate the role of cultural intelligence on self-esteem and family conflict resolutions among athletes.

Methods: The research method was correlational analytic and the research society included all married athletes (both male and female) in different sport disciplines of individual and team sports from Shahin Shahr, Isfahan. For this purpose, 180 athletes responded to the research questionnaires using the available sampling method, and finally, 179 questionnaires were analyzed. The research tools were the Cultural Intelligence Questionnaire designed by Erlie \& Ange (2004), Cooper Smith's Self-Esteem Questionnaire (1967), and Rahim's Family Conflict Resolution Questionnaire (2003). Data were analyzed using SPSS V. 23 and AMOS V. 22 software.

Results: The results showed that the only relationship between self-esteem and the motivational dimension of cultural intelligence was significant $(\mathrm{P}<0.05)$. Besides, the relationship between cultural intelligence and its dimensions, except for the behavior dimension with family selfesteem was significant $(\mathrm{P}<0.05)$. Furthermore, the relationship between cultural intelligence and its dimensions with the styles of family conflict resolution was significant $(\mathrm{P}<0.05)$. The results of structural equation modeling also showed that the model of the relationship between cultural intelligence with self-esteem and the styles of family conflict resolution in athletes had a good fit.

Conclusion: Cultural intelligence plays a role in the self-esteem and resolution of athletes' family conflicts.

\section{Introduction}

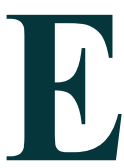

xercise is an activity, through which people can maintain their physical and mental health and improve it. Athletes not only enjoy a suitable state of physi- cal fitness but also act better than other people behaviorally and mentally. The effect of sport on personality traits is an addressed topic in exercise psychology. From the viewpoint of researchers, sports activities provide a safe environment for acquiring cultural values and consequently, promoting cultural intelligence [1]

* Corresponding Author:

Zohreh Meshkati, PhD.

Address: Department of Motor Behavior, Faculty of Physical Education and Sport Sciences, Isfahan (Khorasgan) Branch, Islamic Azad University, Isfahan, Iran

Phone: +98 (13) 5354135

E-mail: zmeshkati@gmail.com 
Irley and Patterson defined cultural intelligence as the ability to collect, process, and perform data in multicultural environments. Cultural intelligence allows individuals to identify how others think and respond to behavior patterns [2]. Besides, cultural intelligence provides the ability to predict effective cultural judgment and decision-making about proper adaptation and performance [3]. Cultural intelligence has four meta-cognitive, cognitive, motivational, and behavioral dimensions. Barnardo and Presbitero believe that cognitive cultural intelligence is the knowledge about the norms, practices, customs, and rules of a diverse cultural environment that are acquired through personalized training and experiences. While metacognitive cultural intelligence is the way of perception and planning in different cultural experiences, motivational cultural intelligence is the ability to concentrate, direct, and spend energy on learning and behaving in different cultural situations, which demonstrates the individual's interest, belief, the movement toward cross-cultural adaptation, and the ability to deal with cross-cultural challenges and stay steady. However, the behavioral dimension of cultural intelligence is concerned with verbal and nonverbal behaviors in cultural interactions. Therefore, cultural intelligence with these dimensions is an important approach to overcome individual problems, such as family conflict resolution.

In the process of the family life cycle, some issues and problems emerge that are related to family functions at the micro level; in this regard, the family experiences transformations, which has led to conflicts among family members [4]. Conflict is the apparent debate at least between two people, in which the person feels that the lack of facilities, incompatibility of goals, and interference of others prevents him/her from achieving his/her goals [5]. Although conflict and resolving it is a part of each culture, the way, through which it is understood, expressed, and dealt with varies from one culture to another one [6]. Studies have shown a positive relationship between the dimensions of conflict resolution styles and personality, emotional intelligence, and cultural intelligence $[7,8]$. There is a significant relationship between cultural intelligence and conflict resolution techniques [9, 10]. Also, Yeke and Semercioz found a significant relationship between personality traits and cultural intelligence with communication abilities [11]. Ramirez showed that cultural intelligence affects people's attitudes toward individual abilities, such as conflict resolution and self-esteem [12].

Self-esteem is a set of thoughts, feelings, emotions, and experiences, which is formed in the process of social life [13]. People with high self-esteem have traits, such as mental maturity, stability, realism, tranquility, high abil- ity to endure failure. However, people who suffer from low self-esteem do not respect themselves and it may result in their isolation, aggression, or anti-social behaviors. Self-esteem plays an important role in having the sense of ability to attempt for becoming a deserving person [14]. Self-esteem can affect people's thoughts, feelings, and behaviors [10]. People with high self-esteem have more and greater goals and are keen to face new situations and topics to use their talent and strengths. Thus, self-esteem can be an effective factor in individual success [15]. Ahmadi et al. [16] reported that self-esteem and attitudes toward sport explain women's sport participation. Cultural barriers play an important role in women's sport participation. Given the necessity of sport for women, the changes in cultural patterns should be considered [17]. Personality traits, such as self-esteem affect intercultural social interactions more when the cultural intelligence among individuals is greater.

Kargarfard and Khoshnam [18] showed a significant relationship between cultural intelligence with selfesteem and family conflict resolution in both male and female athletes and higher cultural intelligence increased athletes' self-esteem and improved their family conflict resolution skills.

Based on what was described and the literature review, some challenges, such as economic and social problems of athletes and the length of time that they devote to exercise, can cause more conflicts in the family. However, the development of positive conditions through exercise can create a sense of self-efficacy in people, which increases their self-esteem and reduces their anxiety. Athletes acquire attitudes, values, and skills, by which they can resolve family conflicts and improve their selfesteem by promoting cultural intelligence. There is a relationship between cultural intelligence and conflict resolution management $[6,17,18]$. Besides, cultural intelligence is strongly associated with some intercultural training methods, the duration of intercultural training, and the intensity of cultural immersion with conflict resolution skills [7]. In addition, Sports participation improves cultural intelligence in athletes, which consequently increases their self-esteem and family conflict resolution. Therefore, this research was done to investigate the role of cultural intelligence on self-esteem and family conflict resolution among athletes.

\section{Methods}

The present study was a correlational analysis. The statistical population included male and female married athletes in different sport disciplines of individual and team 
sports from Shahin Shahr, Isfahan, in 2018. The study sample was calculated to be 179 individuals (male and female athletes from individual and team sports) according to the Cochran formula, which was selected by the available sampling method. Gall et al. [19] considered the minimum sample size of 15 subjects for each predictor variable in multivariate regression analysis. Thus, this sample size seems sufficient. The age range of the participants was 20-40 years. Inclusion criteria were as follows: age range of 20 to 40 years, being an athlete, including team or individual sport at least three days a week for one to one and a half hours, being married, including permanent marriage for at least 5 years, and having at least one child. Exclusion criteria were those younger than 20 years or more than 40 years, performing exercise less than three days a week, being single or divorced, having no children, or being married for less than five years.

\section{Measuring tools}

\section{Cultural Intelligence Questionnaire (CQS)}

This questionnaire designed by Ang et al. [20] was used to measure cultural intelligence. It is a self-report questionnaire consisting of 20 questions scoring on a five-point Likert scale with four metacognitive, cognitive, motivational, and behavioral subscales. Items one to four were related to metacognitive subscale, items five to 11 were related to cognitive subscale, items 12 to 15 assessed motivational subscale, and items 16 to 20 assessed behavioral subscale. The internal consistency is reported high, Cronbach's alpha was above 0.7 for all subscales, and the reliability of this questionnaire was obtained 0.866 using Cronbach's alpha [21]. Asghari and Roshani reported the validity of 0.724 for this tool by calculating its correlation coefficient through Karami's cultural intelligence scale and 0.702 through total correlation coefficient with criteria question. Besides, the reliability of this tool using Cronbach's alpha and split-half methods was 0.934 and 0.912 , respectively [22]. In this study, the coefficient of validity using Cronbach's alpha for the whole questionnaire was 0.89 and for metacognitive, cognitive, motivational, and behavioral dimensions was $0.75,0.83,0.82$, and 0.78 , respectively.

\section{Self-esteem Questionnaire}

Cooper Smith developed his self-esteem scale based on a revision on the Rogers and Damond scale. This test has 58 yes-no questions. The score for the answer "YES" was one and the score for the answer "NO" was zero, and the minimum and maximum score would be zero and 50, respectively. Eight items of the scale (question
$26,32,36,41,45,50,53$, and 58) were lie detector so that if the respondent score of more than 4 out of the 8 lie detectors reveals that the test result was not reliable and the subject has tried to appear better than he/she is. Also, 50 items are divided into 4 subscales (general self-esteem, social self-esteem, family self-esteem, and academic self-esteem). This scale is beneficial because it is applicable to different ages [23]. Various internal studies have confirmed the validity and reliability of this questionnaire. Boroumand [24] standardized this questionnaire on students and reported its reliability of 0.89 . Besides, to measure the validity of this tool, its correlation with the Eiseng questionnaire was calculated to be 0.814 . In this study, the reliability coefficient using Cronbach's alpha for the whole questionnaire was 0.79 and for its dimensions, including general self-esteem, social self-esteem, family self-esteem, and academic selfesteem was $0.74,0.78,0.76$, and 0.7 , respectively.

\section{Family Conflict Resolution Questionnaire (ROCI-II)}

This 28-item questionnaire measures five conflict resolution styles on a 5-point Likert scale ranging from very low (1 point) to very high ( 5 points). The styles of the questionnaire and their definitions are as follows:

1. Integration style: It requires high regard to both one's own and others' concerns that is ultimately, the win-win situation.

2. Bound Style: It requires low regard to one's own concerns and high regard for others' concerns that is ultimately, a loser-win situation.

3. Dominant style: It requires high regard for one's own concerns and low regard for others' concerns that is ultimately, a win-lose situation.

4. Avoidance style: It requires low regard for both one's own and others' concerns that is ultimately, the loser-loser situation.

5. Compromise style: It requires moderate attention for both one's own and others' concerns and a moderate stance that is ultimately neither a win-win nor lose-lose situation.

In order to assess the validity, a positive and negative correlation was found between the subscales of Rahim's conflict resolution questionnaire and the marital conflict resolution questionnaire, which indicates the proper convergent and divergent validity of the questionnaire [25]. The reliability of the questionnaire was also calculated 
to be 0.8 using Cronbach's alpha method [25]. In this study, the coefficients of reliability were calculated using Cronbach's alpha for the questionnaire styles, including integration, bound, dominant, avoidance, compromise to be $0.88,0.75,0.74,0.72$, and 0.95 , respectively.

Data collection was done using the field and library methods. For collecting theoretical data and research literature, library resources, the Internet, and papers were used. Then, the questionnaires were used to collect data. To distribute the questionnaires, the sports complexes were coordinated for cooperation through the Cultural Welfare Recreation Department of Shahin Shahr. The time schedule table of the sports complexes was received to plan for presence at adult sport time. At class arrival, the research topic was described to athletes, their questions about this research were answered, they signed the informed consent form, and the questionnaires were distributed among them. In this case, the researcher could answer the athletes' questions or doubts, if they had any. The questionnaires were distributed and collected during four weeks.

\section{Data analysis}

Descriptive and inferential statistics were used to analyze data through SPSS V. 23 and AMOS V. 22 software. Besides, to test the hypotheses, correlation analysis and structural equation modeling were used.

\section{Results}

The results showed that 61 participants $(34.1 \%)$ were male and 118 participants $(65.9 \%)$ were female. Besides, 72 participants $(40.2 \%)$ had an athletic spouse and 103 participants $(57.5 \%)$ had a non-athletic spouse. Other demographic characteristics are presented in Table 1.

Table 2 presents the descriptive findings, including mean, standard deviation, and minimum/maximum score of the research variables. Kolmogorov-Smirnov results are presented for testing the normality of the scores and internal correlation of the research variables.

Table 1. Demographic characteristics of the participants

\begin{tabular}{|c|c|c|}
\hline \multicolumn{2}{|c|}{ Demographic Variables } & \multirow{2}{*}{$\begin{array}{c}\text { No. (\%) } \\
9(5)\end{array}$} \\
\hline \multirow{7}{*}{ Education } & Under diploma & \\
\hline & Diploma & $54(30.2)$ \\
\hline & Associate degree & 29 (16.2) \\
\hline & & \\
\hline & Bachelor's degree & $61(34.1)$ \\
\hline & Master's degree and above & $26(14.5)$ \\
\hline & total & $179(100)$ \\
\hline \multirow{4}{*}{ Economic Status } & Weak & $9(5.0)$ \\
\hline & Moderate & $140(78.2)$ \\
\hline & Good & 30 (16.8) \\
\hline & Total & 179 (100) \\
\hline \multirow{7}{*}{ Competition level } & School & $54(30.2)$ \\
\hline & Zone & $22(12.3)$ \\
\hline & Province & $14(7.8)$ \\
\hline & Country & $31(17.3)$ \\
\hline & International & $8(4.5)$ \\
\hline & No response & $50(27.9)$ \\
\hline & Total & $179(100)$ \\
\hline
\end{tabular}


Table 2. Descriptive findings, normality test results, and internal correlation of the research variables

\begin{tabular}{|c|c|c|c|c|c|c|c|c|c|c|c|}
\hline & Variable & Mean $\pm S D$ & $\begin{array}{l}\text { Min. } \\
\text { Score }\end{array}$ & $\begin{array}{l}\text { Max. } \\
\text { Score }\end{array}$ & Statistics & Sig. & $\begin{array}{c}\text { Cultural } \\
\text { Intelligence }\end{array}$ & $\begin{array}{c}\text { Meta } \\
\text { Cognitive }\end{array}$ & Cognitive & $\begin{array}{c}\text { Motiva- } \\
\text { tional }\end{array}$ & $\begin{array}{c}\text { Behav- } \\
\text { ioral }\end{array}$ \\
\hline \multirow{5}{*}{ 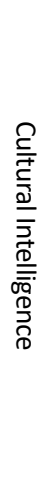 } & $\begin{array}{c}\text { Cultural } \\
\text { Intelligence }\end{array}$ & $91.82 \pm 19.47$ & 41 & 135 & 0.051 & 0.2 & & & & & \\
\hline & $\begin{array}{c}\text { Meta } \\
\text { cognitive }\end{array}$ & $21.42 \pm 4.69$ & 6 & 28 & 0.061 & 0.2 & & & & & \\
\hline & Cognitive & $30.08 \pm 8.06$ & 9 & 49 & 0.016 & 0.2 & & & & & \\
\hline & Motivational & $19.27 \pm 5.74$ & 8 & 28 & 0.019 & 0.2 & & & & & \\
\hline & Behavioral & $21.03 \pm 6.68$ & 8 & 35 & 0.056 & 0.2 & & & & & \\
\hline \multirow{4}{*}{ 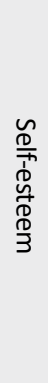 } & Self-esteem & $27.01 \pm 3.13$ & 17 & 34 & 0.042 & 0.2 & 0.091 & 0.132 & -0.001 & $0.159 *$ & 0.033 \\
\hline & General & $14.29 \pm 2.16$ & 9 & 19 & 0.038 & 0.2 & 0.006 & 0.047 & -0.0108 & 0.091 & 0.034 \\
\hline & $\begin{array}{c}\text { Social } \\
\text { self-esteem }\end{array}$ & $4.4 \pm 1.14$ & 1 & 7 & 0.055 & 0.2 & 0.033 & 0.063 & 0.007 & 0.087 & -0.018 \\
\hline & $\begin{array}{c}\text { Family } \\
\text { self-esteem }\end{array}$ & $4.59 \pm 1.23$ & 1 & 7 & 0.048 & 0.2 & $0.0244^{* *}$ & $0.207^{* *}$ & $0.196^{* *}$ & $0.227^{* *}$ & 0.13 \\
\hline \multirow{6}{*}{ 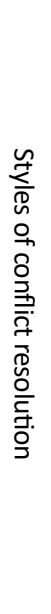 } & Work place & $3.68 \pm 1.001$ & 1 & 7 & 0.069 & 0.2 & -0.057 & -0.013 & 0.013 & 0.077 & -0.105 \\
\hline & $\begin{array}{l}\text { Integration } \\
\text { style }\end{array}$ & $28.03 \pm 5.31$ & 7 & 35 & 0.053 & 0.2 & $0.46^{* *}$ & $0.448^{* *}$ & $0.302^{* *}$ & $0.38^{* *}$ & $0.315^{* *}$ \\
\hline & Bound Style & $14.96 \pm 3.72$ & 5 & 25 & 0.052 & 0.2 & $-0.159^{*}$ & $-.0153^{*}$ & $-.0178^{*}$ & -0.019 & -0.118 \\
\hline & $\begin{array}{l}\text { Dominant } \\
\text { style }\end{array}$ & $21.22 \pm 4.14$ & 7 & 30 & 0.018 & 0.2 & $0.375^{* *}$ & $0.225^{* *}$ & $0.265^{* *}$ & $0.305^{* *}$ & $0.25^{* *}$ \\
\hline & $\begin{array}{l}\text { Avoidance } \\
\text { style }\end{array}$ & $19.26 \pm 4.15$ & 7 & 30 & 0.013 & 0.2 & $-0.32^{* *}$ & $-0.27^{* *}$ & $-0.275^{* *}$ & $-0.225^{* *}$ & $-0.209^{* *}$ \\
\hline & $\begin{array}{l}\text { Compromise } \\
\text { style }\end{array}$ & $15.07 \pm 2.84$ & 4 & 20 & 0.033 & 0.2 & $0.39^{* *}$ & $0.418^{* *}$ & $0.266^{* *}$ & $0.271^{* *}$ & $0.272^{* *}$ \\
\hline
\end{tabular}

${ }^{*} \mathrm{P}<0.05 ;{ }^{* *} \mathrm{P}<0.01$

IRH'

As it can be seen in Table 2, the results of the Kolmogorov-Smirnov test showed that all research variables had a normal distribution $(\mathrm{P}<0.05)$. Moreover, the results of the Pearson correlation test showed that the relationship between self-esteem and cultural intelligence was significant only for its motivational dimension $(\mathrm{P}<0.05)$. However, the relationship between total self-esteem and cultural intelligence and metacognitive, cognitive, and behavioral dimensions was not significant $(\mathrm{P}<0.05)$. The model of the relationship between cultural intelligence with self-esteem and the styles of family conflict resolution among athletes is presented in Figure 1. 


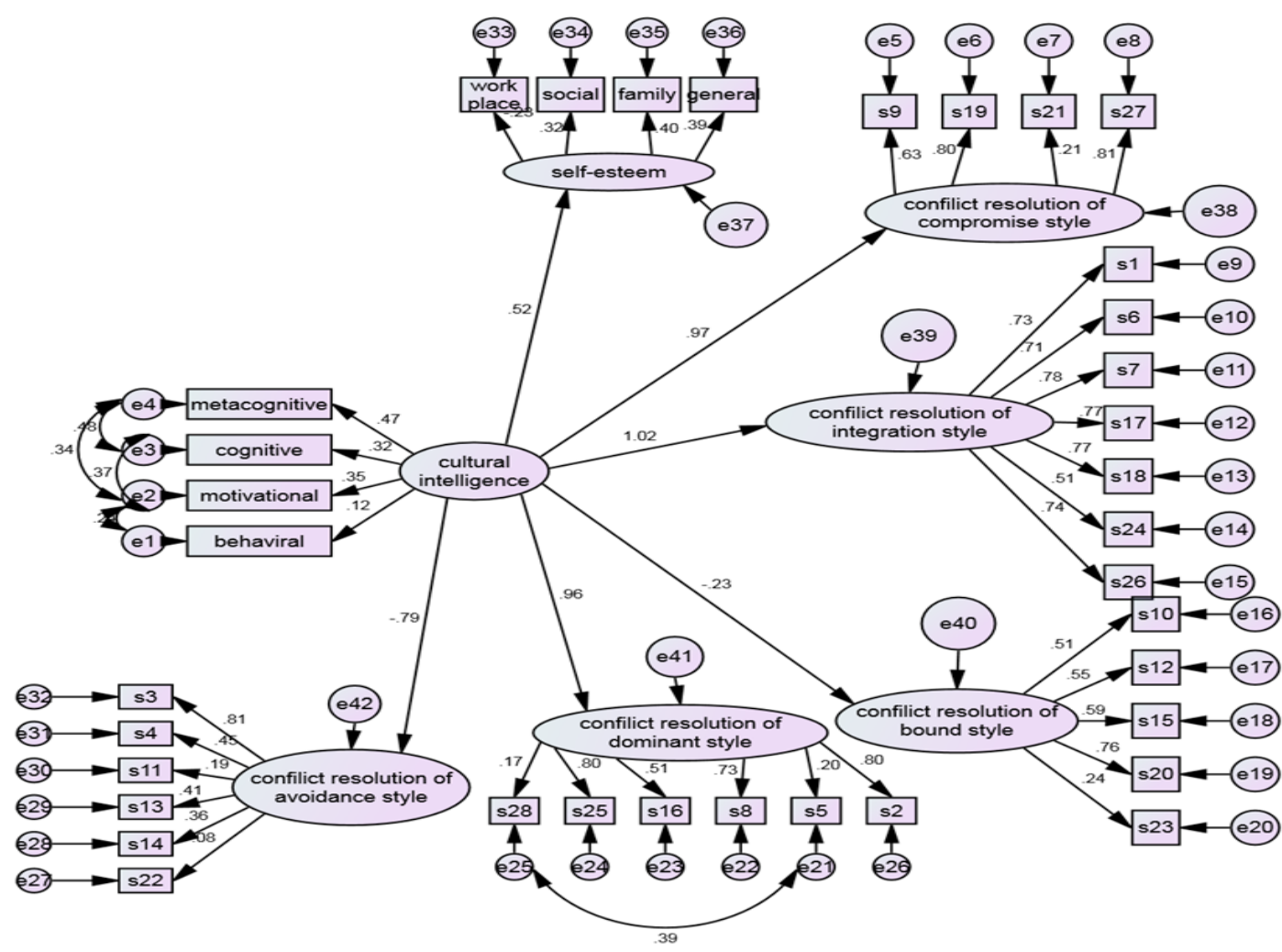

MPA

Figure 1. The model of Relationship between Cultural Intelligence with self-esteem and the styles of family conflict resolution among athletes

The general indices of model fitness are presented in Table 3. According to Table 3, the relative Chi-square index was 1.924 for the model. It indicates that this index is proper. The value of the Tucker-Lewis Index (TLI) and Comparative Fit Index (CFI) comparative indices was about 0.9. Also, the Parsimonious Comparative Fit Index (PCFI) value as the goodness of fit index was higher than 0.5 and desirable. The Root Mean Squared Error of Approximation (RMSEA) value, as the most important overall fit index, was 0.072 , indicating that the model has a good fit generally. The Holter index was also 106 and indicated that the sample size was sufficient to check the fitness of the model.
Table 4 presents the results of the direct effects of the relationship between cultural intelligence with self-esteem and athletes' family conflict resolution styles.

As it can be seen in Table 4, the effect of cultural intelligence on self-esteem (0.552), cultural intelligence on integration (0.999), cultural intelligence on bound style (0.962), the effect of cultural intelligence on avoidance style (-0.796), and the effect of cultural intelligence on compromise style (-0.974) at the level of 0.001 , and cultural intelligence on dominant style $(-0.228)$ at the level of 0.01 was significant.

Table 3. General fit indicators in the model of the relationship between cultural intelligence with self-esteem and family conflict resolution styles fit indices

\begin{tabular}{|c|c|c|c|c|c|c|c|c|}
\hline \multirow{2}{*}{$\begin{array}{l}\text { Other } \\
\text { Holter }\end{array}$} & \multicolumn{3}{|c|}{ Economical } & \multicolumn{2}{|c|}{ Comparative } & \multicolumn{3}{|c|}{ Absolute } \\
\hline & RMSEA $^{8}$ & $\mathrm{CMIN} \backslash \mathrm{DF}^{7}$ & $\mathrm{PCFI}^{6}$ & $\mathrm{CF}^{5}$ & $\mathrm{TLI}^{4}$ & $\mathrm{P}^{3}$ & $\mathrm{DF}^{2}$ & $\mathrm{CMIN}^{1}$ \\
\hline 106 & 0.072 & 1.924 & 0.725 & 0.882 & 0.865 & 0.001 & 584 & 1123.763 \\
\hline \multicolumn{4}{|c|}{ 1. Chi-Square; } & \multicolumn{4}{|c|}{ 5. Comparative Fit Index; } & IRAH \\
\hline \multicolumn{4}{|c|}{ 2. Degree of Freedom; } & \multicolumn{5}{|c|}{ 6. Parsimonious Comparative Fit Index; } \\
\hline \multicolumn{4}{|l|}{ 3. P value; } & \multicolumn{4}{|c|}{ 7. Normed Chi-Square; } & \\
\hline \multicolumn{4}{|c|}{ 4. Tucker-Lewis Index; } & \multicolumn{5}{|c|}{ 8. Root Mean Squared Error of Approximation. } \\
\hline
\end{tabular}


Table 4. Estimation of the direct effects in the model of the relationship between cultural intelligence with self-esteem and athletes' family conflict resolution styles

\begin{tabular}{cccccc}
\hline Parameter & Standard Estimation & Sig Level & Critical Proportion & $\begin{array}{c}\text { Unstandardized } \\
\text { Estimation }\end{array}$ & Sig. \\
\hline Cultural intellige $\rightarrow$ Self esteem & 0.523 & 0.001 & 2.507 & 0.109 & 0.012 \\
\hline Cultural intelligence $\rightarrow$ Integration & 0.999 & 0.001 & 4.408 & 0.342 & 0.001 \\
\hline Cultural intelligence $\rightarrow$ Dominant & -0.228 & 0.001 & -2.134 & -0.062 & 0.03 \\
\hline Cultural intelligence $\rightarrow$ Bound & 0.962 & 0.001 & 2.276 & 0.098 & 0.023 \\
\hline Cultural intelligence $\rightarrow$ Avoidance & -0.796 & 0.001 & -2.953 & -0.039 & 0.041 \\
\hline Cultural intelligence $\rightarrow$ Compromised & 0.974 & 0.001 & 4.109 & 0.255 & 0.001 \\
\hline
\end{tabular}

\section{Discussion}

The results of structural equation modeling showed that cultural intelligence had a significant effect on selfesteem and marital conflict resolution styles. These results are in line with the findings of Zartoshtiyan and Gholamipour [9] and Ahmadi et al. [10] who demonstrated the significant association between cultural intelligence and conflict resolution styles. Moreover, the results are in line with the findings of Ozsoy [7] and Reguieg [8] who showed a positive relationship between the dimensions of conflict resolution styles and personality, emotional intelligence abilities, and cultural intelligence. Consistent with these results, Kargarfard and Khoshnam [18] have also shown that by increasing athletes' cultural intelligence, their self-esteem increases and it improves their family conflict resolution skills.

First, the cultural and ethnic diversity in the study group should be noted. In order to explain the similarity between the results of this study to those of previous studies, it can be said that cultural intelligence is the ability to learn new patterns in cultural interactions and react properly to these patterns. Therefore, a person with high cultural intelligence is prepared to understand cultural differences and to take powerful actions accordingly. Therefore, cultural intelligence helps individuals to control and manage intercultural and intercultural differences more effectively. A person who has a high level of cultural intelligence understands cultural fences and is aware of them as the frame of his/her behavior, by which the way of thinking and reacting in different situations is justified [26].

Besides, cultural intelligence and the ability to resolve conflicts at work and in the family are essential requirements of the $21^{\text {st }}$ century because the more people interact, the more significant the cultural differences [27].
Therefore, a high level of cultural intelligence among athletes makes them identify, understand, and express their individual differences with their spouse better, which increases their ability to resolve marital conflicts. The results of this study confirm that people with higher cultural intelligence will probably be able to understand their spouse in conflict situations and express their emotions more easily and prevent prolonged conflicts and as a result, they have more desirable relationships. Also, because they are able to understand individual differences, they use appropriate conflict resolution styles, such as integration, dominant, bound, avoidance, and compromise styles when needed.

\section{Conclusion}

In explaining the effect of cultural intelligence on athletes' self-esteem, it should be noted that cultural intelligence, as the ability to face cultural situations, is an appropriate interaction ability, which is seen in people's behavior and motivation. For instance, people with high cultural intelligence show proper behaviors based on their verbal and nonverbal abilities. They can use the right words and tone, and language. Intelligence is an important capability for athletes because they deal with different cultures in the sports environment. On the other hand, Ang et al. argued that people with higher cultural intelligence are aware of cultural differences in interactions and cultural intelligence affects individuals' communication and consequently, self-efficacy and self-esteem. Selfesteem reflects one's belief in his/her own abilities and values. Dong et al. believe that people with higher cultural and social intelligence experience life more meaningful. Therefore, cultural intelligence is associated with the ability to resolve conflicts and positive interpersonal experiences, such as self-esteem. Thus, it is obvious that personal differences, such as cultural intelligence, by 
which people understand personal differences better help them to manage their reaction to others' viewpoint about themselves better and increase their self-esteem.

One of the limitations of this study was the sampling method, which was limited to the time and statistical population of athletes in Shahin Shahr, Isfahan. Therefore, the generalization of the results should be done with caution. To compensate for this limitation, conducting further studies in a longer period of time and in other societies is recommended. Besides, self-reporting is another limitation of the present study. The results of this study showed that cultural intelligence affects athletes' self-esteem and their ability to resolve family conflicts; thus, it is suggested that sports counselors and psychologists, as well as athletes, enhance their cultural intelligence through appropriate training to improve their selfesteem and ability to resolve conflicts. In addition, future studies are suggested to not only study the impact of other aspects of intelligence, such as emotional and spiritual intelligence on individual and family characteristics of athletes but also investigate the effectiveness of educational interventions on athletes' cultural intelligence and its impact on individual and family variables.

\section{Ethical Considerations}

\section{Compliance with ethical guidelines}

This study was approved by the Ethics Committee of the Islamic Azad University, Isfahan (Khorasgan) Branch (Code: 99-04-14-2-1381).

\section{Funding}

The author (s) received no financial support for the research, authorship, and/or publication of this article.

\section{Authors' contributions}

Study design: Fahmideh Soltani, Zohreh Meshkati; Data collection and analysis, manuscript preparation: Fahmideh Soltani; Both authors have read and approved the final version of the manuscript.

\section{Conflict of interest}

The authors declared no conflict of interest.

\section{References}

[1] Persbitero A, Toledano LS. Global team members' performance and the roles of cross-cultural training, cultural intelligence, and contact intensity: The case of global teams in IT offshoring sector. Int J Hum Resour Man. 2018; 29(14):2188-208. [DOI:10.1080/09585192.2017.1322118]

[2] Barnardo A, Presbitero A. Belief in polyculturalism and cultural intelligence: Individual- and country-level differences. Pers Individ Dif. 2017; 119:307-10. [DOI:10.1016/j. paid.2017.08.006]

[3] Young CA, Haffajee B, Corsun DL. The relationship between ethnocentrism and cultural intelligence. Int J Intercult Relat. 2017; 58:31-41. [DOI:10.1016/j.ijintrel.2017.04.001]

[4] Mokhtarnia I, Zademohamadi A, habibi M, Mirzaieefar F. [Marital conflicts and parent-adolescent conflicts: The mediator role of adolescents' appraisals of interparental conflicts (Persian)]. J Family Res. 2017; 12(4):663-82. https://jfr.sbu. ac.ir/article_97458.html

[5] Bertoni A, Bodenmann G. Satisfied and dissatisfied couples: Positive and negative dimensions, conflict styles and relationships with family of origin. Eur Psychol. 2010; 15(3):175-84. [DOI:10.1027/1016-9040/a000015]

[6] Deng L, Gibson P. A qualitative evaluation on the role of cultural intelligence in cross-cultural leadership effectiveness. Int J Leadersh Stud. 2008; 3(2):181-97. https://researchrepository.rmit.edu.au/esploro/outputs/journalArticle/Aqualitative-evaluation-on-the-role-of-cultural-intelligence-incross-cultural-leadership/9921860816301341

[7] Ozsoy M. Conflict management styles and type a personality. Proceedings of the fifth European academic research conference on global business, economics, finance and banking (EAR 16 Turkey Conference). 15-17 December 2016; Istanbul, Turkey, 2016. http://www.globalbizresearch.org/ Turky_Conference_2016_Dec/docs/doc/3.\%20\%20Management $\% 20 \& \% 20$ Marketing/1612.pdf

[8] Reguieg S. Conflict resolution skills and cultural intelligence: exploring relationships and antecedents [PhD. dissertation] Los Angeles: Alliant International University Los Angeles; 2014. https://www.google.com/books/edition/Conflict Resolution_Skills_and_Cultural/NNoGjwEACAAJ?hl=en

[9] Zartoshtiyan S, Gholami Torkslooye S, Eydipour K, Kord N, Bakhit M. Relationship between the dimensions of cultural intelligence with ability to solve conflict the general directorate of youth and sport personnel Fars Province. Organ Behav Man Sport Stud. 2015; 2(5):71-8. https:/ / www.sid.ir/en/ Journal/ViewPaper.aspx?ID=506583

[10] Ahmadi A, Safarzade H, Hoozoori MJ, Dehnavi F. [The role of cultural intelligence of managers on employees' conflict resolution ability (Persian)]. Soc Cogn. 2013; 2(3):101-6. [DOI:10.5267/j.msl.2013.06.037]

[11] Yeke S, Semercioz F. Relationship between personality traits, cultural intelligence and intercultural communication competence. Procedia Soc Behav Sci. 2016; 235:313-9. [DOI:10.1016/j.sbspro.2016.11.036]

[12] Ramirez AR. Impact of cultural intelligence level on conflict resolution ability: A conceptual model and research proposal. Emerg Leadersh Journeys. 2010; 3(1):42-56. https:// www.regent.edu/acad/global/publications/elj/vol3iss1/ Ramirez_ELJV3I1_pp42-55.pdf 
[13] Tolabi Z, Samadi S, Motaharinejhad F. [The role of mediator of self-esteem and self-efficacy in the relationship between Islamic lifestyle and social adjustment of youth in Mashhad City (Persian)]. J Youth Sociol Stud. 2014; 3(9):115-32. https:// www.sid.ir/fa/journal/ViewPaper.aspx?id=208774

[14] Ishida J. Contracting with self-esteem concerns. JEcon Behav Organ. 2012; 81(2):329-40. [DOI:10.1016/j.jebo.2011.11.002]

[15] Barani M, Zariee E, Falahchayee R. [The relationship between self-esteem and family power structure among satisfactory women and divorce applicants in Bandar Abbas City (Persian)]. Women Fam Stud. 2016; 9(31):23-37. https:/ / www.sid.ir/fa/journal/ViewPaper.aspx?ID=466239

[16] Ahmadi S, Mokhtari M, Zarei H. [The relationship between self-esteem and attitude to sport with sport participation of women using structural equation model (Persian)]. Appl Res Sport Manag. 2016; 4(3):41-52. http://ensani.ir/file/download/article/20160717145049-9937-142.pdf

[17] Norozi A, Maleki A, Parsamehr M, Ghasemi H. [Investigating the effect of body image and body management on women's sports participation in Ilam Province (Persian)]. J Appl Sociol. 2019; 29(4):99-121. https:/ /jas.ui.ac.ir/article_22961.html

[18] Kargarfard A, Khoshnam E. The relationship of cultural intelligence with self-esteem and capability of resolving family disputes of male and female athletes. The $2^{\text {nd }}$ National Congress on Sport and Health Science Achivements. 25 October 2018; Ahvaz, Iran. https://civilica.com/doc/813233/

[19] Gall J, Gall MD, Borg W. Quantitative and qualitative research methods in education and psychology. [Z. Khosravi, AR. Kiamanesh, M. Shahniyeh Yilagh, Kh. Bagheri, M. Khair MJ. Pakseresht, et al, Persian trans.]. Tehran: SAMT; 2017. https://www.adinehbook.com/gp/product/B000PBXTHN

[20] Ang S, Van Dyne L, Koh C, Yee NgK, Templer KJ, Tay C, et al. Cultural intelligence: Its measurement and effects on cultural judgment and decision making, cultural adaptation, and task performance. Manag Organ Rev. 2007; 3(3):335-71. [DOI:10.1111/j.1740-8784.2007.00082.x]

[21] Ghadampour E, Mehrdad H, Jafari HA. [The study of the relationship between personality characteristics and cultural quotient among the personnel of Cultural Heritage, Handicrafts and Tourism Organization of Lorestan Province (Persian)]. J Educ Psychol. 2011; 2(1):81-101. https:/ / www.sid.ir/ fa/journal/ViewPaper.aspx?ID=167275

[22] Asgari P, Roshani KH. [Comparison of cultural intelligence, emotional intelligence, individual and social adjustment of male and female students of Ahwaz Islamic Azad University (Persian)]. Women Cult J. 2013; 3(12):49-63. https:/ / www.sid. ir/fa/journal/ViewPaper.aspx?ID=191711

[23] Salmela-Aro K, Nurmi J-E. Self-esteem during university studies predicts career characteristics 10 years later. J Vocat Behav. 2007; 70(3):463-77. [DOI:10.1016/j.jvb.2007.01.006]

[24] Siyadat M., Jadidi M. [Effect of social skills training on selfesteem and identity dimensions working children (Persian)]. J Educ Psychol. 2015; 11(37):83-101. https:/ /jep.atu.ac.ir/article_3665.html

[25] Haghighi H, Zariee E, Ghaderi F. [Factor structure and psychometric characteristics conflict resolution styles questionnaire Rahim (ROCI-II) in Iranian couples (Persian)]. J Family Counsel Psychother. 2012; 1(4):534-61. https://www.sid.ir/ fa/journal/ViewPaper.aspx?id=160712
[26] Bagherpour M, Mahbobi T, Mahbobi K. [Studying the relationship between cultural intelligence and metacognitive awareness and intelligence beliefs with academic performance (Persian)]. Educ Man Innov. 2017; 11(1):47-59. https:/ / jmte.riau.ac.ir/article_918.html

[27] Templer KJ, Tay C, Chandrasekar NA. Motivational cultural intelligence, realistic job preview, realistic living conditions preview, and cross-cultural adjustment. Group Organ Manag. 2006; 31(1):154-73. [DOI:10.1177/1059601105275293] 
This Page Intentionally Left Blank 